\title{
Cationic Lipoplexes and its Bourgeoning Mechanisms; an Expert Opinion
}

\section{Sankha Bhattacharya*}

Associate Professor, Department of Pharmaceutics, ISF College of Pharmacy,

Punjab, India

*Corresponding Author: Sankha Bhattacharya, Associate Professor, Department of Pharmaceutics, ISF College of Pharmacy, Punjab, India.
Received: January 31, 2020

Published: February 08, 2020

(C) All rights are reserved by Sankha

Bhattacharya.
Now a day's cationic lipid has become an essential and vital tool for transferring DNA into the cytocellular membrane [1]; which is ultimately helps in gene therapy. In this direction, cationic lipids are being mixed with DNA to form cationic lipid DNA complex or Lipoplexes [2]. For in vivo applications of Lipoplexes, it is precondition to have excess positive and excess negative charge ratio for gene transfer [3]. Although Lipoplexes are good carrier for gene therapy, but actual transfection activity is not clear for Lipoplexes [4]. For making Lipoplexes a stable formulation, it is necessary to have proper lipid and DNA charge ratio in it [5]. The Figure 1 explaining the morphology and cytocellular behaviour of Lipoplexes.

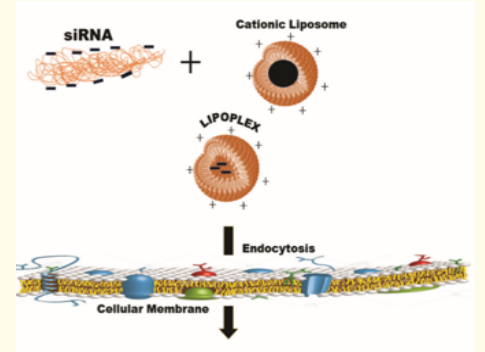

Figure 1: Behaviour of Lipoplexes in cellular membrane.

It is very important to understand that the cationic liposomes predicament with DNA which forms aggregated vesicles on the DNA[6]. When the charge ratio appears 1:1; indicating ideal conditions for liposome to fuse with DNA. After lipid/DNA encapsulation, it resembles like a rod shape structure inside of DNA encapsulated lipid bilayer membrane [7]. Usually, Lipoplexeses are releases from endosomes (endosomes are membrane-bound vesicles, formed via a complex family of processes collectively known as endocytosis) by flip-flap mechanism. Some fuogenic lipids like 1,2-dioleoyl-snglycero-3-phosphocholine (DOPE) are in effective use to enhance transfection efficacy as because it enables Lipoplexes to fuse with endosomal membrane [8], which ultimately leads to release of DNA 16 polymers and nanocomposites for gene therapy. In the year 1995, Gustafsson and co-workers identified Cryotransmission electron micrographs forms clustered of aggregated particles when added with DNA [9]. As far as Lipoplexes utilization is concerned; they are versatilely used in gene therapy as because Lipoplexes adsorb more effectively to the anionic plasma membrane of mammalian cells via electrostatic interactions [10]. The Lipoplexes has the eventual tendency to transfection in numerous cell lines but the mechanism in which DNA transform from the Lipoplexes to cell nucleus is still unknown [11]. However, various factors are responsible for successful DNA delivery viz. structure of cationic reagent, super molecular structure of Lipoplexes, intercellular localization, DNA carriers and their release patters, helper lipids in cationic liposomes [12].

When we are talking about structure of Lipoplexes in details, they form large aggregates surrounded by thin fibers or condensed DNA coated by bilayer of lipid; almost like beads on a string [13]. From the X-ray diffraction studies it was confirmed that Lipoplexes occurs in multilamellar structure with DNA monolayers sandwiched between cationic membranes and in hexagonal structure or in honeycomb assembly. To understand postulated Transfection mechanism of Lipoplexes, kindly referee figure 2.

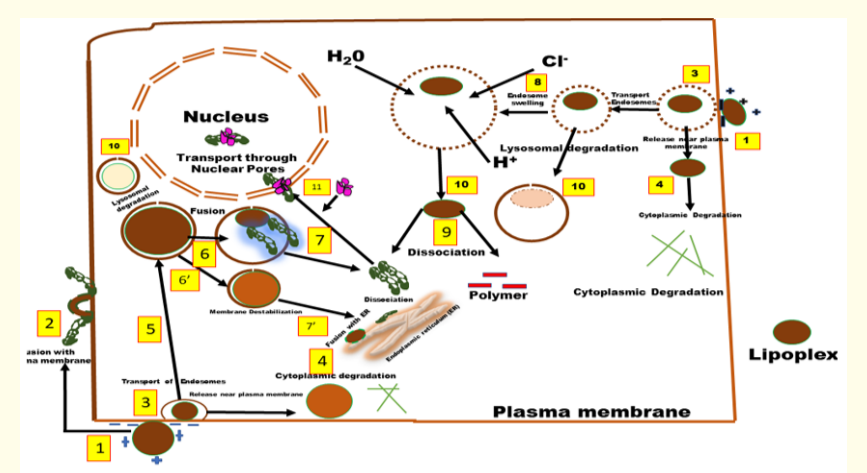

Figure 2: Transfection mechanisms of Lipoplexes within Plasma membrane to Nucleas.

Postulated mechanism [14] which involved various steps for Lipoplexes mediated transfection was reported in Figure 2. The dark brown colour ellipse represented as Lipoplexes. In this diagram, red colour rod shape objects represent as lipids or polymers and green colour coiled objects represents Plasmid DNA. The yellow colour numbers represent significates steps involved in the mechanism. Number 1, represents in the absence of serum binding of vectors to the cells; which involved mainly electrostatic interactions. Number 2 represents, fixation of Lipoplexes with plasma membrane without entering of DNA into the cytoplasm. The Number 3 signifies the initiation of Endocytosis which boost internalization of Lipoplexes 
inside of the cell. The Number 4 represents, The DNA degradation because of limited presence of endosomes which results in release of Lipoplexes in too early stage. In Number 5 upbringing of transfecting materials was explained near to the perinuclear region because of activating transport of cytoplasmic endosome. The actual aspect of transfection represents, DNA must escape from endosomes before entering into the nucleus. In Number 6, lipid-lipid interactions or fusion was represented. The Number 6 signifies membrane destabilization and lipid transfer mechanism. The Number 8 represents osmatic rupture of endosomes, the Number 7 represents, dissociation of Lipoplexes resulting in separation of DNA and vector. In Number 7 the fusion of released Lipoplexes with cytoplasmic network such as ER was shown. The Number 9 represents the dissociation of Lipoplexes in the cytoplasm by yet unknown mechanism. The Number 10 represents, lysosomal degradation of Lipoplexes which are unable to escape from endosomes. DNA released from Lipoplexes or polyplexes into the cytoplasm may enter the nucleus via two different, non-mutually exclusive, Mechanism. The Number 11 represents energy dependent nuclear transport into the nucleus. The presence of specific sequence of plasmid, mediates its interactions with proteins such as transcription factors. The nuclear signal-mediated transport mechanism helps in DNALipid/Protein complex transport into the nucleus. Recent findings also anticipate that, Lipoplexes-filled endosomes may fuse directly with the nuclear membrane, permitting a direct entry of DNA into the nucleus.

\section{Conclusion}

Over the decade numerous researches glorifies the progress of Lipoplexes as far as cellular pathways and Mechanism is concerned. But actual Mechanism involved in DNA transfer from lipid core membrane to nucleus is lucid. The escape of Lipoplexes from endosome and DNA entry into the nucleus are not fully tacit. Nevertheless, various vectors presence in the cells has dissimilar transfection efficiencies; depending on the cell type and transfection conditions. It is often seen that in the presence of specific vector certain Lipoplexes shows higher transfection efficacy in stipulated conditions but in the same condition other Lipoplexes are showing no results. That means, specific vectors are needed for specific applications of Lipoplexes unless a universal vector emerge in near future. Additionally, more fundamental research is warrant to understand Lipoplexes cyto cellular behaviour.

\section{Bibliography}

1. Stephens DJ and R Pepperkok. "The many ways to cross the plasma membrane". Proceedings of the National Academy of Sciences 98.8 (2001): 4295-4298.

2. Zhdanov R., et al. "Cationic lipid-DNA complexes-lipoplexes-for gene transfer and therapy". Bioelectrochemistry 58.1 (2002): 53-64.

3. Schatzlein A. "Non-viral vectors in cancer gene therapy: principles and progress". Anti-cancer Drugs 12.4 (2001): 275-304.
4. Ma B., et al. "Lipoplex morphologies and their influences on transfection efficiency in gene delivery". Journal of Controlled Release 123.3 (2007): 184-194.

5. Zelphati O., et al. "Stable and monodisperse lipoplex formulations for gene delivery". Gene Therapy 5.9 (1998): 1272-1282.

6. Lleres D., et al. "DNA condensation by an oxidizable cationic detergent. Interactions with lipid vesicles". Chemistry and Physics of Lipids 111.1 (2001): 59-71.

7. Ulrich AS. "Biophysical aspects of using liposomes as delivery vehicles”. Bioscience Reports 22.2 (2002): 129-150.

8. Ross PC., et al. "Multilamellar cationic liposomes are efficient vectors for in vitro gene transfer in serum". Journal of Liposome Research 8.4 (1998): 499-520.

9. Almgren M., et al. "Cryotransmission electron microscopy of thin vitrified samples". Current Opinion in Colloid and Interface Science 1.2 (1996): 270-278.

10. Okeley NM and MH Gelb. "A designed probe for acidic phospholipids reveals the unique enriched anionic character of the cytosolic face of the mammalian plasma membrane". Journal of Biological Chemistry 279.21 (2004): 21833-21840.

11. Audouy S., et al. "Serum as a modulator of lipoplex-mediated gene transfection: dependence of amphiphile, cell type and complex stability". The Journal of Gene Medicine: A cross-disciplinary journal for research on the science of gene transfer and its clinical applications 2.6 (2000): 465-476.

12. Lonez C., et al. "Cationic liposomal lipids: from gene carriers to cell signalling". Progress in Lipid Research 47.5 (2008): 340347.

13. Adikwu MU and CO Esimone. "Biopolymers in drug delivery: recent advances and challenges". 2010: Bentham Science Publishers (2010).

14. Elouahabi A and JM Ruysschaert. "Formation and intracellular trafficking of lipoplexes and polyplexes". Molecular therapy 11 (2005): 336-347.

\section{Assets from publication with us}

- Prompt Acknowledgement after receiving the article

- Thorough Double blinded peer review

- Rapid Publication

- Issue of Publication Certificate

- High visibility of your Published work

Website: www.actascientific.com/

Submit Article: www.actascientific.com/submission.php Email us: editor@actascientific.com

Contact us: +919182824667 